Economia e Sociedade, Campinas, Unicamp. IE. http://dx.doi.org/10.1590/1982-3533.2021v30n2art03

\title{
Diversificação produtiva da manufatura brasileira *
}

\author{
Milene Simone Tessarin \\ Paulo César Morceiro *** \\ Joaquim José Martins Guilhoto ${ }^{\text {****, ****** }}$
}

\begin{abstract}
Resumo
Este estudo fez uma análise exploratória da diversificação produtiva brasileira com informações oficiais inéditas de plantas multiprodutos obtidas da Pesquisa Industrial Anual do IBGE. O estudo é inovador por apresentar dados diretos de produção de plantas multiprodutos e elaborar um parâmetro para comparação entre os setores diversificados e não diversificados. Outro diferencial refere-se ao elevado nível de desagregação setorial, que inclui cerca de 100 setores da manufatura. Os resultados apontam que a parcela dos setores com empresas que diversificam a produção é pequena, contudo, é representativo em termos de receita líquida de vendas e valor da produção. Os indicadores econômicos da parcela diversificada mostraram-se mais significantes e se ampliam conforme o nível de diversificação aumenta. Constatou-se que setores de baixa e média-baixa tecnologia tendem a diversificar mais para setores próximos (intra-indústria) enquanto alta e média-alta tecnologia diversificam tanto para setores intra como inter-indústria.
\end{abstract}

Palavras-chave: Diversificação, Plantas multiprodutos, Base produtiva, Indústria brasileira.

\section{Abstract}

\section{Productive diversification in the Brazilian manufacturing industry}

This study carried out an exploratory analysis of Brazilian productive diversification using official unpublished information on multiproduct plants obtained from the IBGE's Annual Industrial Survey. The study is innovative given that it presents direct production data from multiproduct plants and elaborates a parameter for comparison between diversified and nondiversified sectors. Another differential refers to the high level of sectoral disaggregation, which includes about 100 manufacturing sectors. Results show that the share of sectors with companies that diversify production is small, albeit representative in terms of net sales revenue and production value. The economic indicators for the diversified share are more significant and grow as the level of diversification increases. Low and medium-low tech sectors tend to diversify more towards close sectors (intra-industry) while high and medium-high technology sectors engage in both intra and interindustry diversification.

Keywords: Diversification, Multi-product plants, Productive base, Brazilian manufacturing. JEL: L22, D23, O33.

* Artigo recebido em 27 de março de 2020 e aprovado em 19 de julho de 2020. Foi realizado com apoio da Coordenação de Aperfeiçoamento de Pessoal de Nível Superior (CAPES) - Código de Financiamento 001. Os autores agradecem os pareceristas e editores da Economia e Sociedade pelos comentários recebidos, assim como os membros do Núcleo de Economia Regional e Urbana da USP (NEREUS-USP) pelas discussões deste trabalho.

${ }^{* *}$ Pós-doutoranda, DST/NRF South African Research Chair (SARChI) in Industrial Development, University of Johannesburg, Africa do Sul. E-mail: milenetessarin@alumni.usp.br. ORCiD: https://orcid.org/0000-0003-2922-8335.

${ }^{* * *}$ Pós-doutorando, DST/NRF South African Research Chair (SARChI) in Industrial Development, University of Johannesburg, Africa do Sul. E-mail: paulo.morceiro@ alumni.usp.br. ORCiD: https://orcid.org/0000-0002-9548-0996.

***** Professor da Universidade de São Paulo, São Paulo, SP, Brasil. E-mail: joaquim.guilhoto@oecd.org. ORCiD: https://orcid.org/0000-0002-7098-1209.

***** Economista da Organização para Cooperação e Desenvolvimento Econômico (OCDE), Paris, França. O conteúdo desta publicação expressa a visão deste autor e não necessariamente representa a visão da OCDE ou dos seus países membros. 


\section{Introdução}

A relação entre a diversificação produtiva e o desempenho econômico vem se tornando uma questão de interesse crescente na literatura. De acordo com Rodrik (2014), o desenvolvimento econômico caminha lado a lado com a diversificação produtiva. Dentre os motivos que levam as empresas a se diversificarem estão manter o crescimento elevado (Schumpeter, 1942; Penrose, 1959); proteger-se de eventuais choques na demanda (Teece, 1982; Koren; Tenreyro, 2013; Zahavi; Lavie, 2013); evitar a saturação do mercado (Aoki; Yoshikawa, 2002; Hausmann; Rodrik, 2003); promover o desenvolvimento tecnológico e potencial inovativo (Granstrand; Patel; Pavitt, 1997; Garcia-Vega, 2006; Kim; Lee; Cho, 2016); e, consequentemente, aumentar a produtividade e o lucro (Palepu, 1985; Granstrand, 1998; Koren; Tenreyro, 2013).

No Brasil, estudos realizados a partir de meados dos anos 1980 mostraram que a diversificação da produção se concentra em uma parcela pequena de empresas, em geral, de grande porte. Tais estudos se basearam em informações de amostras de empresas (Miller, 1981; Barros; Sidsamer, 1983; Kretzer, 2015) e em medidas proxy para chegar ao valor da produção diversificada (Holanda Filho, 1983) devido à escassez de dados mais desagregados.

Neste trabalho foram empregados dados inéditos de plantas multiprodutos, obtidos através de uma tabulação especial da Pesquisa Industrial Anual Empresas (PIA-Empresa) de 2013, do IBGE ${ }^{1}$, para verificar como a diversificação produtiva se estendeu entre os setores produtivos nos anos recentes. Os setores manufatureiros foram divididos em dois grupos: a parcela que possui plantas produtivas diversificadas e a parcela com plantas não diversificadas. Desta forma foi possível alcançar o objetivo de investigar o nível de diversificação produtiva dos setores da manufatura brasileira e comparar seu desempenho em relação à parcela não diversificada. Também foi observado qual o tipo de diversificação mais realizado, ou seja, se os setores diversificados destinaram sua produção a setores que apresentavam características próximas (produtivas e tecnológicas) ou não.

Os resultados apontam que ainda é uma parcela pequena de empresas que tem a capacidade de diversificar sua produção no período recente. No entanto, são empresas representativas em termos de receita líquida de vendas e valor da produção. Quanto à parcela diversificada, na média, a produção realizada pela indústria de transformação em outros subsetores que não o principal, corresponde a $30 \%$. Há uma diferença entre os subsetores quando observados a partir das categorias de intensidade tecnológica. Foi verificado que subsetores de baixa e média-baixa tecnologia tendem a diversificar mais para subsetores próximos, que compartilham características produtivas. Já os subsetores de alta e média-alta, além de diversificarem para próximos, também têm capacidade para atuar em subsetores distantes, que possuem características distintas do principal. Por fim, verificou-se que subsetores com empresas diversificadas possuem melhores resultados econômicos. Quanto maior o nível da diversificação, maior a diferença nos indicadores econômicos encontrados.

O presente estudo é inovador por apresentar dados diretos de produção de plantas multiprodutos, que são bastante raros na literatura nacional. Ele também se diferencia por fornecer um parâmetro para comparação entre os setores diversificados e não diversificados, uma vez todos os

(1) Agradecemos o fundamental apoio dos técnicos do IBGE responsáveis pela PIA-Empresa que se disponibilizaram a discutir as informações e elaboraram os dados. 
estudos prévios abordaram apenas a parte diversificada, sem a respectiva contraposição. Outro diferencial refere-se ao nível de desagregação setorial, que é bastante elevado e inclui cerca de 100 setores da manufatura, o que permitiu uma análise das especificidades setoriais detalhadamente.

Após esta introdução, a seção 1 aborda aspectos teóricos sobre a relevância da diversificação produtiva no contexto das empresas, pré-requisitos envolvidos e abordagens feitas pela literatura brasileira. A seção 2 apresenta conceitos metodológicos. Na seção 3 estão os resultados, com a comparação dos setores diversificados e não diversificados, uma análise detalhada da diversificação setorial e dos diferentes níveis de diversificação entre os subsetores. Após são apresentadas as conclusões

\section{Referencial teórico}

\subsection{Importância da diversificação produtiva}

Diversos autores relevantes pautaram-se no progresso técnico para explicar o crescimento das nações (Schumpeter, 1942; Solow, 1957; Romer, 1990; Aghion; Howitt, 1992). No contexto microeconômico, a diversificação das atividades produtivas das empresas também tem papel decisivo para promover o crescimento, o qual refletirá em última instância sobre a diversificação produtiva dos países (Schumpeter, 1942; Penrose, 1959; Jacobs, 1969; Koren; Tenreyro, 2013).

O crescimento não ocorre apenas por produzir mais do mesmo, ele envolve mudanças técnicas e organizacionais, inovação e novas formas de gerenciar a produção e a cadeia de insumos (Kretzer, 2015). As empresas precisam se empenhar em remodelar suas capacitações e conhecimentos, ajustando as habilidades para diversificar os bens produzidos (Teece, 1982). Por isso, muitos produtos notadamente estão relacionados em termos produtivos e utilizam tecnologias de várias safras tecnológicas (Robertson; Patel, 2007). Bernard, Redding e Schott (2010) identificaram que metade das empresas americanas alteram seu mix de produtos (a 5 dígitos da classificação industrial internacional ISIC), em média, a cada cinco anos, e que essa troca de produtos está correlacionada com os atributos da empresa e do produto. As novas linhas de produtos vão ter certa similaridade com as linhas antigas porque, com o tempo, as firmas adicionam atividades que estão em algum aspecto relacionadas com os produtos já existentes em seu portfólio, apontando para uma coerência dos negócios (Teece; Winter, 1994). Isso significa que o portfólio de produtos combina características e competências que levam a firma a obter benefícios de todas as suas áreas.

Dado que o crescimento está relacionado com a diversificação, então quais são as razões específicas das firmas para diversificarem sua produção? Penrose (1959) foi pioneira ao abordar o tema e apontou três razões centrais. A primeira é evitar que seu crescimento seja limitado pela taxa de expansão da demanda dos bens que produz. A segunda é que lhe permite aproveitar novas oportunidades de produção utilizando conhecimentos que já possui. E a terceira é que dá margem de manobra para responder a problemas específicos, como flutuações temporais da demanda. Outros motivos relevantes incluem produzir com economias de escala e de marketing e estender a confiança que o consumidor já tem sobre um produto para outros do seu portfólio (Penrose, 1959). Teece (1982) e Koren e Tenreyro (2013) sugerem um argumento similar ao de Penrose (1959). Para eles, as empresas almejam mitigar impactos de choques externos que afetam a produtividade de um dos produtos individualmente. Assim, um número maior de variedades ajuda a empresa a reduzir a 
volatilidade das operações (Koren; Tenreyro, 2013; Zahavi; Lavie, 2013), por isso, quanto mais opções, mais fácil será se adaptar a imprevistos e choques na demanda.

Garcia-Vega (2006) aponta que a diversificação das firmas pode prevenir um efeito de lockin em uma tecnologia particular, o que ajuda a renovar os negócios da empresa e a sustentar seu crescimento no mercado. A diversidade tecnológica beneficia a empresa ao abrir novas possibilidades de produção, uma vez que alguns problemas podem ser resolvidos a partir de conhecimento e tecnologia existentes em setores não relacionados diretamente (Rumelt, 1974; Saviotti; Pyka, 2004).

Outra razão bastante citada na literatura é que as empresas estão preocupadas com a saturação da demanda sobre seus produtos e, por isso, realizam esforços para evitá-la através da produção em diferentes setores (Aoki; Yoshikawa, 2002; Hausmann; Rodrik, 2003; Koren; Tenreyro, 2013). Novos produtos ou setores de atuação podem substituir setores tradicionais nos quais a demanda tem crescimento limitado e naqueles em que o lançamento de produtos inovadores está eliminando nichos do mercado que um dia foram mais dinâmicos.

Argumentos relacionados ao desenvolvimento tecnológico também são bastante recorrentes. A diversificação traz um efeito positivo para as firmas em termos do aumento do investimento em $\mathrm{P} \& \mathrm{D}$, da ampliação das conexões entre setores e novas tecnologias e do envolvimento com tecnologias relacionadas a novos negócios (Granstrand; Patel; Pavitt, 1997), além do aumento da atividade inovativa, verificado pelo número de patentes (Garcia-Vega, 2006). Utilizar recursos tecnológicos de forma eficiente leva a uma sinergia entre múltiplas linhas de produtos, o que inclui promover economias de escopo na atividade de P\&D e no alcance de sua base de conhecimento (Kim; Lee; Cho, 2016). Além disso, a diversificação tecnológica aumenta a capacidade de absorção da firma e, portanto, sua competência tecnológica em explorar e assimilar conhecimentos fora de suas fronteiras (Cohen, Levinthal, 1990; Garcia-Vega, 2006; Kim; Lee; Cho, 2016).

Em geral, a maximização de valor mediante a captura de sinergias é o coração do incentivo à diversificação (Teece, 1982). Em termos de desempenho, a diversificação produz uma melhora nos resultados financeiros e no crescimento da empresa (Granstrand, 1998; Kim; Lee; Cho, 2016) e melhor aproveitamento de recursos via economias de escopo em termos produtivos e tecnológicos (Teece, 1982; Zahavi; Lavie, 2013). Há também um aumento na produtividade e lucratividade das empresas que diversificaram a sua produção, especialmente para áreas relacionadas às competências centrais (Koren; Tenreyro, 2013; Palepu, 1985). Portanto, diversificar a produção tornou-se um imperativo, mais do que apenas uma escolha estratégica das empresas, em que ter um portfólio variado é importante para concorrer com firmas que possuem um catálogo vasto de produtos.

\subsection{As bases necessárias para a diversificação}

O conceito de base produtiva de Penrose (1959) é utilizado para explicar como a firma pode diversificar e corresponde a "cada tipo de atividade produtiva que usa máquinas, processos, qualificações e matérias-primas complementares entre si e que são interligados uns aos outros no processo produtivo, independentemente do número ou dos tipos de produtos produzidos" (Penrose, 1959, p. 97). Assim, uma empresa pode possuir várias bases produtivas com elementos que as relacionem. Por sua vez, a diversificação permite que o conjunto de competências ou capacidades centrais da firma seja reforçado (Kim; Lee; Cho, 2016) e ampliado a partir da junção de capacidades 
que se complementam. Esse compartilhamento possibilita que empresas explorem recursos subutilizados, reduzam os custos de produção e aumentem o valor do produto final (Zahavi; Lavie, 2013).

A ideia é que uma base produtiva envolve todos os requisitos necessários para a produção, sendo que muitos deles são itens comuns para mais de um produto. Assim, produzi-los conjuntamente permite às empresas organizá-los de modo a obter o melhor aproveitamento de todos os seus recursos. Nesta situação são verificadas economias de escopo (Hausmann; Rodrik, 2003), as quais tornam mais barato para a firma produzir um produto novo aproveitando boa parte da base produtiva instalada, ao invés de ter que implementar uma base totalmente nova.

Essencialmente, uma base produtiva concentra competências centrais que sustentam a produção em si, seus melhoramentos e a geração de inovações. Algumas competências genéricas formam um leque maior de oportunidades de diversificação, por exemplo, tecnologias de produção sem propósito específico, que permitem fazer diversas combinações e gerar produtos diferentes. Nesse sentido, a capacidade da empresa em combinar competências e técnicas organizacionais é decisiva para o processo de diversificação (Teece, 1982), assim como a capacidade de absorver conhecimentos gerados em bases distintas, ou seja, de aproveitar os spillovers ${ }^{2}$. Los (2000) apontou uma distinção útil entre duas classes de spillovers de conhecimento. A primeira tem uma forte natureza intra-industrial e se apoia em transbordamentos de conhecimento e ideias produzidas em outros setores manufatureiros ao utilizar a imitação e a engenharia reversa para internalizar esses conhecimentos. A segunda classe é mais autônoma e foi chamada de "criadoras de ideias", pois surgem de informações públicas (em patentes ou publicações), da relação usuário-fornecedor, em negociações comerciais, dentre outras formas. Ambas têm o potencial de transformar a base de conhecimento e incluir novas oportunidades de produção.

Inevitavelmente, identificar e integrar competências exigirá investimento em aprendizado interno (Granstrand; Patel; Pavitt, 1997). Para entrar em novas áreas de atuação, a empresa precisa descobrir os custos de produzir com lucro nessa nova atividade, porém, algumas imperfeições no mercado fazem com que os cálculos sejam dificultados (Rodrik, 2014), principalmente devido ao componente tácito do conhecimento. Hausmann e Rodrik (2003) chamaram atenção para um processo intitulado self-discovery, no qual defendem que as firmas conseguem capturar apenas uma parte do valor inicial que um novo conhecimento gera. Nesse sentido, a diversificação produtiva envolve custos que vão além de questões operacionais ou conhecimentos preestabelecidos e que não podem ser desconsiderados.

Há também algumas condições externas que facilitam o processo de diversificação das empresas. Com pequenas adaptações, alguns fatores comuns podem ser utilizados para reduzir os custos de se produzir mais de um produto, estimulando a decisão de compartilhar a base produtiva. Segundo Teece (1982), a natureza da firma tem um importante componente tácito, que é o conhecimento individual, mas ele é limitado pelas habilidades e experiências existentes. Uma forma de estocar o conhecimento operacional na organização é através da roteirização das atividades. Assim,

(2) Granstrand, Patel e Pavitt (1997) lembram que combinar competências envolve também um custo considerável, uma vez que grandes gastos são necessários para adaptar, coordenar e aprender tecnologias distintas. Por isso, as empresas devem estar financeiramente bem estruturadas. 
o conhecimento aplicado para a produção de um produto pode ser replicado para outros que utilizam bases produtivas similares. A expertise produtiva da firma está em utilizar essa "memória organizacional" para ampliar as possibilidades de produção.

Em geral, a diversificação tende a ocorrer para áreas com similaridades produtivas e tecnológicas. A complexidade dos produtos apresentada por Hausmann et al. (2013) e Hidalgo et al. (2007) elucida bem essa questão. Produtos mais complexos são aqueles que possuem uma rede de conexão mais ampla e, consequentemente envolvem competências propícias para a produção de outros produtos. Os autores mostraram que há uma rede de produtos que são mais prováveis de serem co-exportados pelos países ao considerarem que, a partir da fabricação de um produto, é mais fácil fabricar alguns outros que compartilham características técnico-produtivas.

\subsection{Diversificação no Brasil}

Poucos estudos tratam da diversificação de empresas no Brasil e inexistem investigações que verifiquem a composição setorial da atividade produtiva de firmas diversificadas. Em geral, são mais comuns pesquisas agregadas sobre a concentração econômica do mercado ou poder de monopólio (que é muitas vezes tratado como o oposto da diversificação). Isso ocorre principalmente pela indisponibilidade de dados.

Em meados dos anos 1980, Holanda Filho (1983) identificou essa carência na análise da estrutura produtiva brasileira. Segundo ele, a empresa diversificada era pouco estudada porque era vista como ineficiente no sentido de que sua produtividade tenderia a ser menor à medida que o conjunto de recursos produtivos da firma fosse empregado em inúmeros produtos. No entanto, ele direcionou esforço para provar que essa afirmação não corresponde à realidade e realizou uma análise pioneira para o Brasil.

Os resultados do trabalho de Holanda Filho (1983) basearam-se em dados das declarações do Imposto sobre Produtos Industrializados (IPI) do ano de 1974 para estimar o valor da produção de 20 setores de atividade. Foi encontrado um grau de diversificação significativamente maior entre as empresas de grande porte em relação às médias, e destas em comparação com as pequenas. Também se apurou que $23 \%$ da produção das empresas diversificadas foi efetuada em setores secundários. Este percentual manteve-se relativamente constante entre os grupos por porte, exceto no caso de grandes empresas (algumas apresentaram mais de 50\% da produção em outros setores).

Partindo de outra base de dados, Barros e Sidsamer (1983) fizeram um estudo para analisar a diversificação da indústria brasileira no ano de 1970, utilizando informações por empresas para 69 setores industriais da matriz de relações intersetoriais do IBGE. Os autores verificaram que $72 \%$ dos setores da economia apresentavam um índice de participação na produção principal alto associado a um baixo índice de diversificação. Miller (1981) elaborou um trabalho no mesmo período (para o ano de 1974) a partir de dados das 500 maiores empresas industriais que operavam no Brasil e estabeleceu uma relação entre diversificação e tamanho dessas empresas, mostrando que quanto maior, mais diversificada.

Ardissone (2009) apontou alguns fatores que contribuíram para a diversificação das atividades produtivas no período de 1996 a 2005, a partir da avaliação da distribuição espacial das 
atividades industriais no Brasil com dados da Pesquisa Industrial Anual - PIA-Empresa (para empresas com 30 ou mais trabalhadores). Segundo a autora, no final dos anos 1990, com a maior concorrência no mercado nacional, os investimentos passaram a ser feitos visando aquisições, busca por novos mercados e diversificação das atividades. Uma parte das empresas que se encontravam defasadas tecnologicamente investiram em modernização e diversificação da produção para atender a mais segmentos do mercado e aumentar sua rentabilidade.

A diversificação empresarial do Brasil também foi tratada por Kretzer (2015), o qual a observou em termos de atividade produtiva e localização geográfica (para o período de 2006 a 2010), com base nas informações do Cadastro Central de Empresas do IBGE, agregando-as por porte. Ele encontrou que a maioria das firmas do país, independente do porte, apresenta baixo nível de diversificação da atividade econômica. Identificou também que elas optam por expandir a produção na mesma planta industrial ou na mesma região do que instalar novas unidades em outras regiões. No entanto, ao tratar das empresas com atividades produtivas diversificadas, Kretzer (2015) não aborda a composição da produção distribuída entre as atividades em que a empresa atua.

Recentemente, Tessarin (2018), ao avaliar 24 setores manufatureiros (CNAE a dois dígitos) com dados da PIA-Empresa de 2013, encontrou que, em média, 30\% da produção da indústria de transformação foi realizada por plantas produtivas diversificadas, ou seja, por unidades produtivas que produziram bens típicos de mais de um subsetor industrial. Comparativamente, a diversificação aumentou frente ao apontado por Holanda Filho (1983), quando encontrou 23\% de firmas diversificadas na década de 1980. É relevante lembrar que a atividade industrial brasileira está se desadensando, conforme identificado por Morceiro e Guilhoto (2020), o que significa que há menor transformação industrial e maior montagem de componentes e insumos importados. Nesse contexto, as oportunidades para diversificação se tornam mais restritas.

Em síntese, há poucos estudos sobre diversificação produtiva no Brasil e algumas questões importantes inexploradas sobre esse tema, principalmente sobre o período recente. Esta pesquisa busca contribuir com o tema ao diminuir as seguintes lacunas: primeiro, os estudos sobre a diversificação de empresas brasileiras estão defasados e são pouco específicos setorialmente; segundo, a diversificação não foi apresentada pela ótica de plantas produtivas (somente pela abordagem da empresa como conglomerado) ${ }^{3}$; e terceiro, talvez a mais importante, não há nenhuma análise que mostre como a produção diversificada se distribui entre os subsetores.

\section{Fonte das informações e procedimentos metodológicos}

As informações foram coletadas a partir da planta industrial ou unidade local (UL) de forma independente do seu grupo empresarial. Os dados utilizados são inéditos, pois provêm de uma tabulação especial da Pesquisa Industrial Anual Empresa (PIA-Empresa), elaborada pela Diretoria de Pesquisas da Coordenação de Indústria do IBGE (IBGE, 2013). Foram solicitados dados referentes às UL dos subsetores da indústria de transformação para o ano de 2013. Será utilizada a Classificação

(3) Holanda Filho (1983) citou que seus resultados para empresas de grande porte estão superestimados, uma vez que a maioria delas participa de conglomerados que possuem mais de uma planta industrial, mas que a partir da sua abordagem dos dados não é possível captá-las individualmente. 
Nacional de Atividades Econômicas (CNAE) versão 2.0, desagregada a três dígitos, que apresenta 103 grupos ou subsetores de atividade na indústria de transformação.

De acordo com a metodologia de levantamento de informações das pesquisas industriais do IBGE (IBGE, 2013), as unidades locais devem informar o valor da produção e da receita líquida de venda de cada item produzido. Então é feita uma correspondência entre produto e subsetor vinculado para verificar qual é o subsetor de atividade principal e os subsetores secundários. O subsetor cujo produto represente a maior parcela da produção será considerado o subsetor principal ou subsetor de origem. Os demais serão identificados como subsetores secundários, sendo o destino para os quais a produção foi diversificada. Se as UL atuantes em um subsetor possuem $100 \%$ de sua produção neste único subsetor, então ele é não diversificado. Já se fabricam produtos do seu subsetor principal e de outros subsetores secundários, é um subsetor diversificado.

O índice de diversificação subsetorial $\left(d_{j}\right)$ será dado por:

$$
d_{j}=\left(\frac{P_{j}^{v}}{P_{j}^{v}+P_{j}^{n v}}\right) * 100
$$

Em que o subscrito $j$ indica os subsetores da indústria de transformação, $P$ corresponde ao valor da produção industrial, $P_{j}^{v}$ indica as plantas industriais que produzem produtos do subsetor de origem $j$ e de subsetores secundários (plantas diversificadas) e $P_{j}^{n v}$ indica as plantas industriais que produzem produtos apenas do subsetor de origem $j$ (plantas não diversificadas).

Para construir a tabulação sobre diversificação, foram selecionadas apenas as informações das UL industriais que atuam nos subsetores da indústria de transformação (equivalente a $98 \%$ da receita total da manufatura), detalhando o valor bruto da produção industrial (VBPI) e a receita líquida de vendas (RLV) em cada subsetor de atividade que há registro de produção.

Não foi imposto um limite para a diversificação, isso significa que, no caso extremo, $1 \%$ da produção pode estar alocada no subsetor principal e $99 \%$ em vários subsetores secundários, ou o contrário. Essa definição de diversificação propositalmente requer uma restrição forte: produzir mais de um produto industrial e na mesma planta. A literatura clássica de diversificação à la Penrose (1959) apontou formas de diversificação mais abrangentes, mas a opção feita visou excluir a diversificação para setores não-industriais (como firmas manufatureiras que realizam sua própria logística) e estratégias do grupo empresarial (como aquisição de outros negócios).

De todo modo, mesmo subsetores que declararam não possuir produção diversificada podem produzir vários itens da mesma família, uma vez que os códigos da classificação setorial são compostos por uma gama de produtos similares e nem mesmo no nível máximo de desagregação seria possível identificar todos eles.

\section{Análise empírica da diversificação produtiva}

\subsection{Diferenciais das plantas industriais diversificadas}

Em 2013, das 188.713 UL com mais de cinco empregados da indústria de transformação brasileira, apenas 2,9\% atuaram em mais de um subsetor de atividade entre os 103 subsetores da indústria de transformação (Tabela 1). Essas são as UL que compõem os subsetores diversificados. 
Embora o número relativo de UL seja pequeno, as plantas diversificadas empregaram $20 \%$ do pessoal ocupado da manufatura, pagaram mais de um quarto dos salários, foram responsáveis por $42 \%$ da RLV e somaram $44 \%$ do VTI na manufatura, formando um grupo de UL industriais representativas da manufatura brasileira em termos econômicos.

Os dados das Tabelas 1 e 2 revelam que as plantas industriais de subsetores diversificados são significativamente maiores, remuneram melhor seus trabalhadores e são mais produtivas relativamente ao conjunto de plantas industriais que atuaram em apenas um subsetor. Além disso, o fato de concentrarem esse percentual de RLV e VBPI denota que dominam seus mercados de atuação.

Tabela 1

Subsetores diversificados e não diversificados da indústria de transformação brasileira, 2013: informações básicas

\begin{tabular}{|c|c|c|c|c|c|c|}
\hline \multirow{2}{*}{ Subsetores } & \multirow{2}{*}{$\begin{array}{c}\text { Unidades } \\
\text { produtivas } \\
\text { (UL) }\end{array}$} & \multirow{2}{*}{$\begin{array}{c}\text { Pessoal } \\
\text { ocupado } \\
(\mathrm{PO})\end{array}$} & Salários (W) & RLV & VBPI & VTI \\
\hline & & & \multicolumn{4}{|c|}{ Em bilhões de R $\$$ correntes } \\
\hline Não diversificados & 183.239 & 6.238 .909 & 155,1 & $1.378,2$ & $1.328,8$ & 542,8 \\
\hline Diversificados & 5.474 & 1.563 .694 & 58,4 & 993,4 & 929,9 & 426,3 \\
\hline Não diversificados (\%) & 97,1 & 80,0 & 72,6 & 58,1 & 58,8 & 56,0 \\
\hline Diversificados $(\%)$ & 2,9 & 20,0 & 27,4 & 41,9 & 41,2 & 44,0 \\
\hline
\end{tabular}

Nota: Planta industrial diversificada produz em mais de um subsetor (grupos da CNAE 2.0) e não diversificada em apenas um subsetor. $\mathrm{UL}=$ unidade local; $\mathrm{RLV}=$ receita líquida de vendas; $\mathrm{VBPI}=$ valor bruto da produção industrial; VTI = valor da transformação industrial.

Fonte: Tabulação especial da PIA-Empresa/IBGE. Cálculos e elaboração dos autores.

Conforme a Tabela 2 mostra, os subsetores com plantas industriais não diversificadas empregaram, em média, 34 trabalhadores contra 286 nas diversificadas. O valor bruto da produção industrial por planta industrial diversificada foi 23,3 vezes maior que nas não diversificadas. $\mathrm{E}$ a agregação de valor por trabalhador (VTI/PO) foi 3,1 vezes superior nas UL diversificadas frente às não diversificadas. Por sua vez, o salário médio (salários/PO) é 50\% maior para os trabalhadores que atuaram nas UL diversificadas.

Tabela 2

Indicadores dos subsetores diversificados e não diversificados da indústria de transformação, 2013

\begin{tabular}{|c|c|c|c|c|c|c|c|c|}
\hline \multirow{2}{*}{ Subsetores } & VTI / UL & VBPI / UL & $\begin{array}{c}\text { RLV / } \\
\text { UL }\end{array}$ & \multirow{2}{*}{$\mathrm{PO} / \mathrm{UL}$} & $\begin{array}{l}\text { VTI / } \\
\text { PO }\end{array}$ & VBPI / PO & RLV / PO & $\mathrm{W} / \mathrm{PO}$ \\
\hline & \multicolumn{3}{|c|}{ Em milhão de R\$ correntes } & & \multicolumn{4}{|c|}{ Em mil $\mathrm{R} \$$ correntes } \\
\hline Não diversificados & 3,0 & 7,3 & 7,5 & 34,0 & 87,0 & 213,0 & 220,9 & 24,9 \\
\hline Diversificados & 77,9 & 169,9 & 181,5 & 285,7 & 272,6 & 594,7 & 635,3 & 37,3 \\
\hline $\begin{array}{l}\text { Razão (diversificados / } \\
\text { não diversificados) }\end{array}$ & 26,0 & 23,3 & 24,2 & 8,4 & 3,1 & 2,8 & 2,9 & 1,5 \\
\hline
\end{tabular}

Nota: ver nota da Tabela 1.

Fonte: Tabulação especial da PIA-Empresa/IBGE. Cálculos e elaboração dos autores. 
Em termos de porte, medido como a razão entre os trabalhadores e o número de UL, as diversificadas mostram-se 8,4 vezes maiores que as não diversificadas e, em termos de receita por UL, a razão foi 24,2 vezes maior a favor das plantas industriais diversificadas ${ }^{4}$. Desse modo, os indicadores da Tabela 2 mostram que os subsetores com plantas industriais diversificadas possuem maior escala, eficiência e desempenho econômico em relação àqueles com plantas industriais não diversificadas. Tessarin et al. (2020) também verificaram que setores próximos da manufatura brasileira se beneficiam mutuamente via spillovers positivos sobre a produtividade e capacidade de investimento.

Vale ressaltar alguns estudos que utilizaram índices de diversificação amplamente conhecidos. Por exemplo, entropia (Hitt; Hoskisson; Kim, 1997; Jacquemin; Berry, 1979; Palepu, 1985) para calcular a proporção do número de segmentos em que a firma opera em relação ao total de vendas de cada segmento. O índice cosseno (Jaffe, 1986), dado pela separação angular entre os vetores, que utiliza a contagem de coocorrência de pares de setores. Jaffe (1986) utilizou o índice cosseno para medir a relação - ou a diversificação - entre temas de pesquisas das empresas. Outros autores partindo da mesma ideia utilizaram dados de patentes de firmas para verificar a relação entre os setores. O Los Index (Los, 2000; Neffke; Henning; Boschma, 2011) buscou capturar a diversidade tecnológica entre os setores ao calcular a similaridade entre os insumos de dois setores baseado nas tabelas de insumo-produto. Los (2000) buscou mostrar que se a diversidade tecnológica for demasiada, não será possível aproveitar transbordamentos tecnológicos.

Outro índice bastante comum é o Herfindhal, que na verdade é conhecido por medir a concentração. Com uma simples adaptação em sua formulação é possível obter a diversificação (Gort, 1962; Gorecki, 1974; Jacquemin; Berry, 1979), que será o complemento do índice de concentração. No entanto, todos esses índices têm como premissa utilizar dados no nível do indivíduo (firma) para compará-lo em relação ao todo (setor). Assim, mensuram um indicador, por exemplo, número de patentes de uma empresa do setor $j$ em relação ao total de patentes do setor $j$. O modo em que os dados foram disponibilizados para esta pesquisa não permite tratá-los individualmente, logo, inviabiliza a aplicação desses tipos de índices.

\subsection{Diversificação produtiva dos subsetores manufatureiros}

A avaliação da diversificação será feita para o ano de 2013 pela ótica a três dígitos da CNAE, que conta com 87 subsetores da indústria de transformação (os demais 16 não apresentaram diversificação). Para facilitar a análise, os subsetores estão organizados por categorias tecnológicas (baixa e média-baixa tecnologia e alta e média-alta tecnologia) da OECD (2003). No trabalho de Tessarin (2018) é possível ver uma análise da diversificação produtiva para os 24 setores da manufatura a dois dígitos da CNAE.

A hipótese é que subsetores conectados partem da mesma base de conhecimento e usam o mesmo conjunto de capacidades produtivas, e por isso têm maior chance de serem produzidos juntos. Mas além dos subsetores com características similares, é interessante destacar aqueles que conseguiram diversificar rumo a subsetores com grandes diferenças entre si, pois isto significa que

(4) A ordem de grandeza a favor das plantas industriais diversificadas comparativamente às não diversificadas mantém-se para os anos mais recentes, de modo que esse resultado não é conjuntural e sim, estrutural. 
houve uma evolução no aprendizado e capacitação tecnológica a ponto de conseguir internalizar diferentes tecnologias e conhecimentos.

Nas Tabelas 3 e 4, a coluna 'dentro do setor principal' indica a diversificação para perto, ou seja, que ocorre quando a produção foi diversificada para outro subsetor dentro do mesmo setor de origem. Na coluna 'outros setores' tem-se a diversificação para longe, a qual ocorre quando o subsetor passa a produzir bens que não fazem parte da mesma família do setor de origem. Por fim, a coluna ' $n^{0}$ de subsetores que atua' apresenta a amplitude da diversificação e indica para quantos subsetores a produção foi diversificada. De acordo com Cohen e Levinthal (1990), quanto maior a capacidade de absorção de conhecimentos da firma, mais apta ela estará para acessar mais conhecimentos e, consequentemente, atuar em novos setores. Para a manufatura brasileira, os subsetores produtivos com conteúdo tecnológico similar possuem relações de vizinhança mais frequentes (Tessarin et al., 2020).

$\mathrm{Na}$ categoria de baixa e média-baixa tecnologia há 52 subsetores que diversificaram sua produção e, na média, 83,6\% da produção é realizada diretamente no subsetor de origem (Tabela 3). Essas duas categorias compõem cerca de dois terços da manufatura brasileira (Morceiro, 2018), portanto há mais opções de diversificação. A diversificação para perto e para longe possui magnitude similar, em torno de $8 \%$ da produção em cada um dos casos. No entanto, há diferenças evidentes no comportamento subsetorial quanto à magnitude e o número de subsetores em que a diversificação ocorre. Conforme Pérez (2010) evidenciou, setores tradicionais e padronizados estão transformandose para agregar valor aos bens produzidos, e assim encontram formas de diversificar a produção utilizando bases produtivas que já possuem e aproveitam requisitos em comum para produzir de modo competitivo. Tessarin, Suzigan e Guilhoto (2020) nos mostram que empresas de baixa e média-baixa tecnologia inovam, principalmente, através da aquisição de máquinas e equipamentos, acessando assim novas tecnologias, um dos meios de chegar à diversificação.

Os três subsetores de baixa e média-baixa tecnologia (Tabela 3) que têm maior capacidade de atuar em outros subsetores são: produtos plásticos; produtos diversos de metal; e abate e produtos de carne. Esses subsetores podem produzir produtos típicos de vários outros segmentos industriais utilizando tecnologias produtivas sobrepostas. Os produtores de artigos plásticos podem atuar na fabricação de tecidos sintéticos, calçados, fibras têxteis e resinas e os fabricantes de produtos de metal podem também atuar na fabricação de tubos de aço, siderurgia, fundição e máquinas-ferramenta, por exemplo.

Outros 13 subsetores diversificaram sua produção em pelo menos dez subsetores diferentes, uma heterogeneidade razoavelmente elevada que garante competências tecnológicas amplas e lhes confere maior potencial para continuar diversificando. Como apontou Saviotti (2008), quanto mais produtos uma empresa produz, maior é seu potencial para produzir outros. No longo prazo, o aprendizado confere à empresa um novo patamar em termos de conhecimento (Saviotti, 2008; Saviotti; Pyka, 2004), que pode resultar em um produto de um subsetor diferente do produto original.

Os casos de diversificação mais expressivos entre os subsetores de baixa e média-baixa tecnologia podem ser divididos em dois grupos. Primeiro, os subsetores que mais diversificaram para perto (ao menos 10\% do VBPI): artefatos de concreto e gesso; outros produtos alimentícios; abate e produtos de carne; e moagem de trigo. Segundo, os subsetores que mais diversificaram para longe (ao menos 10\% do VBPI): produtos diversos de papel; tubos de aço, exceto sem costura; produtos diversos de metal; produtos diversos; móveis; e artigos de cutelaria e ferramentas. 
Tabela 3

Diversificação produtiva dos subsetores manufatureiros de baixa e média-baixa tecnologia, Brasil, 2013

\begin{tabular}{|c|c|c|c|c|c|c|}
\hline $\begin{array}{l}\text { Cód. } \\
\text { CNAE }\end{array}$ & Subsetores a três dígitos & $\begin{array}{l}\text { VBPI total } \\
\text { (milhão de R\$ } \\
\text { correntes) }\end{array}$ & $\begin{array}{c}\text { Subsetor } \\
\text { principal } \\
(\%)\end{array}$ & $\begin{array}{l}\text { Dentro do setor } \\
\text { principal }(\%)\end{array}$ & $\begin{array}{l}\text { Outros } \\
\text { setores } \\
(\%) \\
\end{array}$ & $\begin{array}{c}\mathrm{N}^{\circ} \text { de } \\
\text { subsetores } \\
\text { que atua }\end{array}$ \\
\hline 172 & Papel, cartolina e papel-cartão & 11.740 & 57,0 & 42,6 & 0,4 & 6 \\
\hline 233 & Artefatos de concreto e gesso & 3.749 & 58,1 & 32,9 & 9,0 & 10 \\
\hline 109 & Outros produtos alimentícios & 24.825 & 64,1 & 35,4 & 0,5 & 12 \\
\hline 174 & Produtos diversos de papel & 9.548 & 64,1 & 4,7 & 31,2 & 10 \\
\hline 134 & Acabamentos em artefatos têxteis & 143 & 65,1 & 33,2 & 1,7 & 4 \\
\hline 182 & Serviços de pré-impressão & 600 & 66,0 & 34,0 & 0,0 & 2 \\
\hline 239 & Pedras e minerais não-metálicos & 3.691 & 67,9 & 2,4 & 29,7 & 7 \\
\hline 245 & Fundição & 207 & 68,3 & 0,0 & 31,7 & 2 \\
\hline 122 & Produtos do fumo & 6.199 & 70,1 & 29,9 & 0,0 & 2 \\
\hline 243 & Tubos de aço, exc. sem costura & 5.839 & 70,4 & 7,8 & 21,8 & 10 \\
\hline 133 & Tecidos de malha & 891 & 72,0 & 14,9 & 13,1 & 4 \\
\hline 162 & Produtos de madeira, exc. móveis & 6.869 & 72,2 & 0,8 & 27,0 & 9 \\
\hline 161 & Desdobramento de madeira & 363 & 72,6 & 0,1 & 27,3 & 4 \\
\hline 259 & Produtos diversos de metal & 3.409 & 73,1 & 1,1 & 25,8 & 15 \\
\hline 255 & Equipamento bélico pesado & 406 & 74,4 & 4,7 & 20,9 & 7 \\
\hline 173 & Embalagens de papel & 3.492 & 74,5 & 22,2 & 3,3 & 5 \\
\hline 103 & Conservas de frutas e vegetais & 8.707 & 79,3 & 20,3 & 0,4 & 9 \\
\hline 251 & Estruturas metálicas e caldeiraria & 1.510 & 79,5 & 1,2 & 19,3 & 9 \\
\hline 193 & Biocombustíveis & 2.379 & 80,6 & 0,0 & 19,4 & 3 \\
\hline 232 & Cimento & 14.130 & 80,6 & 19,4 & 0,0 & 3 \\
\hline 329 & Produtos diversos & 1.375 & 82,5 & 0,1 & 17,4 & 12 \\
\hline 151 & Curtimento e preparações de couro & 605 & 83,6 & 7,1 & 9,3 & 6 \\
\hline 101 & Abate e produtos de carne & 101.845 & 83,8 & 14,1 & 2,1 & 14 \\
\hline 132 & Tecelagem, exceto malha & 4.177 & 84,0 & 15,9 & 0,1 & 5 \\
\hline 106 & Moagem de trigo & 14.467 & 84,1 & 13,8 & 2,1 & 12 \\
\hline 112 & Bebidas não alcoólicas & 2.503 & 84,4 & 15,5 & 0,1 & 4 \\
\hline 310 & Móveis & 1.473 & 86,4 & 0,0 & 13,6 & 10 \\
\hline 107 & Refino de açúcar & 20.271 & 86,8 & 0,1 & 13,1 & 3 \\
\hline 234 & Produtos cerâmicos & 2.110 & 87,1 & 5,3 & 7,6 & 6 \\
\hline 104 & Óleos e gorduras & 46.022 & 88,0 & 7,3 & 4,7 & 10 \\
\hline 254 & Artigos de cutelaria e ferramentas & 883 & 88,1 & 0,3 & 11,6 & 12 \\
\hline 105 & Laticínios & 17.276 & 88,4 & 9,5 & 2,1 & 9 \\
\hline 131 & Preparação de fibras têxteis & 980 & 89,7 & 9,2 & 1,1 & 6 \\
\hline 141 & Confecção de vestuário & 8.690 & 90,4 & 0,3 & 9,3 & 10 \\
\hline 111 & Bebidas alcoólicas & 20.434 & 90,5 & 9,3 & 0,2 & 4 \\
\hline 222 & Produtos de plástico & 2.699 & 90,6 & 0,0 & 9,4 & 16 \\
\hline 253 & Forjaria e tratamento de metais & 469 & 90,5 & 8,8 & 0,7 & 4 \\
\hline 154 & Partes para calçados & 129 & 92,0 & 0,0 & 8,0 & 4 \\
\hline 181 & Atividade de impressão & 217 & 92,1 & 0,0 & 7,9 & 3 \\
\hline 108 & Torrefação e moagem de café & 3.232 & 92,7 & 3,6 & 3,7 & 5 \\
\hline 183 & Reprodução de materiais gravados & 218 & 92,7 & 7,3 & 0,0 & 2 \\
\hline 135 & Artefatos têxteis, exc. vestuário & 1.175 & 93,0 & 5,8 & 1,2 & 8 \\
\hline 242 & Siderurgia & 41.227 & 94,6 & 1,4 & 4,0 & 9 \\
\hline 153 & Calçados & 8.408 & 96,1 & 2,4 & 1,5 & 7 \\
\hline 244 & Metalurgia de metais não-ferrosos & 10.645 & 97,6 & 0,0 & 2,4 & 3 \\
\hline 325 & Instrumentos médicos e ópticos & 595 & 97,6 & 0,0 & 2,4 & 2 \\
\hline 221 & Produtos de borracha & 8.976 & 98,5 & 0,0 & 1,5 & 5 \\
\hline 231 & Vidro e produtos do vidro & 958 & 98,5 & 1,2 & 0,3 & 4 \\
\hline 252 & Tanques e reservatórios metálicos & 149 & 98,9 & 0,0 & 1,1 & 2 \\
\hline 192 & Produtos derivados do petróleo & 136.496 & 99,5 & 0,0 & 0,5 & 2 \\
\hline \multicolumn{2}{|c|}{ Média (Baixa e média-baixa tecnologia) } & & 83,6 & 8,4 & $\mathbf{8 , 0}$ & 6,5 \\
\hline
\end{tabular}

Nota: cor cinza destaca valores maiores que $10 \%$ do VBPI do subsetor. Os subsetores 'celulose e outras pastas' e 'ferro-gusa e de ferroligas' possuem menos de $0,5 \%$ da produção diversificada e não foram incluídos na tabela. Fonte: Tabulação especial da PIA-Empresa/IBGE. Cálculos e elaboração dos autores. 
Nota-se que nenhum dos subsetores está nos dois grupos. No caso da diversificação para perto, os subsetores de alimentos são mais presentes. Além deles compartilharem características produtivas, podem aproveitar de condições técnicas como canais de distribuição especializados em produtos semiprocessados, meios de transporte refrigerados, contato com agências de regulamentação e controle de produtos alimentícios, fornecedores de insumos agropecuários, fornecedores de embalagens especializadas, compradores de grande escala e profissionais qualificados (como agrônomo, engenheiro de alimentos, técnico em conservação e qualidade de alimentos, etc.). Este tipo de diversificação para perto retrata o argumento de Jacobs (1969) e Gort (1962) de que o setor principal de atuação tem muita relação com a extensão para a qual a diversificação ocorre e também com os achados de Tessarin et al. (2020) que apontam para uma maior densidade de conexões entre setores próximos.

Quanto à diversificação para longe, os subsetores que formam esse grupo são mais heterogêneos (Tabela 3). Um alto nível de diversificação para longe exibe subsetores que conseguem fazer ajustes na sua capacidade produtiva, aprender novas tecnologias e superar problemas nas linhas de produção. Por isso, eles também estão mais aptos a se reestruturar e superar cenários negativos na demanda ou outra variação pontual em uma de suas áreas de atuação (Koren; Tenreyro, 2013; Zahavi; Lavie, 2013). Assim, como Jacobs (1969) sugeriu, uma maior diversidade setorial contribui para o aprofundamento da diversificação produtiva, uma vez que essas plantas industriais dominam várias áreas de conhecimento e capacidades técnico-produtivas.

Na categoria de alta e média-alta tecnologia (Tabela 4) há 35 subsetores com produção diversificada. A produção realizada no subsetor de origem é de $80,3 \%$, em média, e há uma diferença significativa em favor da diversificação para longe. Em média, $12,5 \%$ da produção foi realizada fora do setor original, enquanto $7,1 \%$ foi feita dentro do mesmo setor. Como apontado, a diversificação para longe exige maior esforço, mas também representa uma habilidade interna inerente aos setores que utilizam tecnologias mais complexas. Esses setores têm domínio sobre tecnologias produtivas mais avançadas e fazem bastante P\&D (Pavitt, 1984). Isso faz com que eles tenham potencial grande para atuar em diversas áreas. Em geral, empresas de maior intensidade tecnológica buscam como estratégia inovativa a manutenção do mercado (Tessarin; Suzigan; Guilhoto, 2020), por isso, uma atuação diversificada contribui para este objetivo.

Nos subsetores de alta e média-alta tecnologia, a diversificação para perto foi mais expressiva para equipamentos de informática e periféricos; e automóveis e utilitários. Já a diversificação para longe ocorreu mais intensamente nos subsetores de aparelhos elétricos diversos; máquinas para extração mineral; e equipamentos para distribuição de energia.

A diversificação para perto ocorreu com maior intensidade nos subsetores que possuem diversas subcategorias. Por exemplo, o código 26 (equipamentos de informática e periféricos) está estruturado em oito subsetores, e o código 29 (automóveis e utilitários) possui cinco, além disso, todos eles possuem uma alta complementariedade na sua produção. Há ainda vários outros subsetores que diversificaram em maior proporção para longe. Metade dos subsetores diversificaram pelo menos $10 \%$ de sua produção para longe do seu subsetor principal (Tabela 4). Essa é uma característica relevante para a categoria de alta e média-alta tecnologia, que confirma que nesse grupo estão os subsetores mais dinâmicos tecnologicamente com competências técnico-produtivas diversas. 
Contudo, as possibilidades de diversificação para os setores de maior intensidade tecnológica são menores proporcionalmente aos de baixa e média-baixa tecnologia, pois, como apontado por Morceiro e Guilhoto (2020), esse setor perdeu densidade nas últimas décadas e, consequentemente, menos elos produtivos estão presentes na estrutura produtiva brasileira.

Tabela 4

Diversificação produtiva dos subsetores manufatureiros de alta e média-alta tecnologia, Brasil, 2013

\begin{tabular}{|c|c|c|c|c|c|c|}
\hline $\begin{array}{l}\text { Cód. } \\
\text { CNAE }\end{array}$ & Subsetores a três dígitos & $\begin{array}{c}\text { VBPI total } \\
\text { (milhão de } \\
\text { R\$ correntes) }\end{array}$ & $\begin{array}{c}\text { Subsetor } \\
\text { principal } \\
(\%)\end{array}$ & $\begin{array}{c}\text { Dentro do setor } \\
\text { principal }(\%)\end{array}$ & $\begin{array}{c}\text { Outros } \\
\text { setores } \\
(\%)\end{array}$ & $\begin{array}{c}\mathrm{N}^{\mathrm{o}} \text { de } \\
\text { subsetores } \\
\text { que atua }\end{array}$ \\
\hline 265 & Instrumentos de medida & 1.497 & 49,5 & 0,0 & 50,5 & 6 \\
\hline 332 & Instalação de M\&E & 91 & 51,8 & 0,0 & 48,2 & 7 \\
\hline 263 & Equip. de comunicação & 16.720 & 59,0 & 41,0 & 0,0 & 6 \\
\hline 209 & Químicos diversos & 2.830 & 63,1 & 0,2 & 36,7 & 3 \\
\hline 264 & Aparelhos de recepção áudio/vídeo & 10.396 & 64,0 & 32,5 & 3,5 & 7 \\
\hline 262 & Equip. de informática e periféricos & 9.781 & 67,6 & 32,3 & 0,1 & 12 \\
\hline 202 & Químicos orgânicos & 36.829 & 69,9 & 29,9 & 0,2 & 8 \\
\hline 286 & Máquinas de uso industrial & 2.080 & 71,6 & 11,0 & 17,4 & 8 \\
\hline 281 & Motores, bombas e compressores & 4.047 & 71,9 & 4,4 & 23,7 & 6 \\
\hline 203 & Resinas e elastômeros & 2.610 & 73,0 & 13,9 & 13,1 & 3 \\
\hline 272 & Pilhas e baterias & 680 & 76,4 & 0,0 & 23,6 & 4 \\
\hline 275 & Eletrodomésticos & 9.674 & 77,3 & 0,0 & 22,7 & 3 \\
\hline 206 & Produtos de limpeza e higiene & 11.683 & 77,5 & 2,9 & 19,6 & 6 \\
\hline 204 & Fibras artificiais e sintéticas & 380 & 77,6 & 0,0 & 22,4 & 7 \\
\hline 284 & Máquinas-ferramenta & 755 & 78,4 & 6,2 & 15,4 & 2 \\
\hline 279 & Aparelhos elétricos diversos & 875 & 80,0 & 0,7 & 19,3 & 10 \\
\hline 283 & M\&E para agricultura e pecuária & 15.101 & 84,1 & 10,1 & 5,8 & 3 \\
\hline 294 & Peças e acessórios para veículos & 12.464 & 84,3 & 0,5 & 15,2 & 9 \\
\hline 271 & Geradores e transformadores & 13.926 & 84,3 & 6,2 & 9,5 & 2 \\
\hline 205 & Defensivos agrícolas & 21.637 & 85,3 & 14,7 & 0,0 & 7 \\
\hline 292 & Caminhões e ônibus & 8.183 & 85,4 & 0,0 & 14,6 & 5 \\
\hline 285 & Máquinas para extração mineral & 3.017 & 86,4 & 1,2 & 12,4 & 14 \\
\hline 261 & Componentes eletrônicos & 40 & 86,6 & 9,1 & 4,3 & 9 \\
\hline 273 & Equip. para distribuição de energia & 2.169 & 86,8 & 1,0 & 12,2 & 15 \\
\hline 267 & Instrumentos ópticos e fotográficos & 7 & 86,9 & 0,0 & 13,1 & 6 \\
\hline 303 & Veículos ferroviários & 363 & 86,9 & 0,0 & 13,1 & 6 \\
\hline 291 & Automóveis e utilitários & 64.303 & 88,4 & 11,6 & 0,0 & 10 \\
\hline 212 & Produtos farmacêuticos & 6.836 & 88,6 & 9,4 & 2,0 & 4 \\
\hline 331 & Manutenção de M\&E & 1.645 & 90,2 & 2,1 & 7,7 & 2 \\
\hline 207 & Tintas e vernizes & 3.351 & 92,1 & 5,6 & 2,3 & 5 \\
\hline 282 & M\&E de uso geral & 3.314 & 95,5 & 0,5 & 4,0 & 19 \\
\hline 293 & Cabines, carrocerias e reboques & 746 & 95,6 & 0,4 & 4,0 & 3 \\
\hline 201 & Químicos inorgânicos & 22.599 & 98,1 & 1,2 & 0,7 & 2 \\
\hline 274 & Lâmpadas e equip. de iluminação & 247 & 99,1 & 0,0 & 0,9 & 9 \\
\hline 309 & Outros equip. de transporte & 9.104 & 99,2 & 0,0 & 0,8 & 4 \\
\hline \multicolumn{2}{|c|}{ Média (Alta e média-alta tecnologia) } & 299.980 & 80,4 & 7,1 & 12,5 & 6,6 \\
\hline
\end{tabular}

Nota: cor cinza destaca valores maiores que $10 \%$ do VBPI do subsetor.

Fonte: Tabulação especial da PIA-Empresa/IBGE. Cálculos e elaboração dos autores. 
Pode-se apontar que a manufatura brasileira possui subsetores de menor intensidade tecnológica que se concentram em competências centrais e diversificam para subsetores próximos tecnologicamente. Já os subsetores de alta e média-alta intensidade tecnológica diversificam relativamente mais para subsetores com características menos similares. Os setores de maior conteúdo tecnológico apresentaram resultado superior em termos de diversificação, apesar da desindustrialização prematura que enfrentam (Morceiro, 2018).

\subsection{Desempenho dos subsetores mais e menos diversificados}

Ao analisar apenas os subsetores que diversificaram sua produção, surge uma questão: níveis de diversificação diferentes apresentam resultados econômicos diferentes? Para dar uma resposta é preciso verificar se há diferença no desempenho dos subsetores mais e menos diversificados. Para tanto, os subsetores foram ordenados a partir do percentual da produção diversificada e divididos em quartis. Comparou-se então os respectivos subsetores com seus pares não diversificados. Assim foi possível calcular a razão entre os resultados dos dois conjuntos (diversificado e não diversificado).

Visando melhor exposição dos dados, a Tabela 5 foi organizada com os resultados apenas dos subsetores do primeiro e do último quartil mais diversificado para o ano de $2013^{5}$. Os resultados baseados na média destes dois quartis demonstram que há diferença de desempenho quando se considera o nível da diversificação. Espera-se que subsetores que produzam bens de vários subsetores tenham acesso a uma maior diversidade de recursos e tecnologias (Holanda Filho, 1983; Garcia-Vega, 2006), o que pode levá-los a obter vantagem econômica da diversificação. Os subsetores mais diversificados (do primeiro quartil) apresentaram desempenho econômico superior ao dos menos diversificados (do último quartil) em todos os indicadores da Tabela 5. O porte das firmas foi 7,5 vezes maior para o conjunto que diversificou mais, enquanto no último quartil essa diferença é de cinco vezes. A produção industrial por planta produtiva (VBPI/UL) ou agregação de valor por planta (VTI/UL) foi o dobro nos subsetores do primeiro quartil em relação aos do último quartil.

Cabe aqui um destaque aos subsetores de equipamentos de comunicação, outros produtos alimentícios, produtos diversos de papel, químicos orgânicos e máquinas de uso industrial, que tiveram desempenho bastante superior em relação à parcela não diversificada. Por exemplo, para o subsetor de equipamentos de comunicação, o VTI por unidade local das plantas diversificadas foi 105 vezes maior que nas plantas não diversificadas. Alguns fatores podem contribuir para essa grande diferença, mas é válido considerar que a diversificação está entre eles, dado que esse perfil se replica para toda a manufatura.

No caso do último quartil mais diversificado, as diferenças nos indicadores são menos marcantes. No subsetor de partes para calçados, as plantas diversificadas têm maior porte, como também um VTI gerado por empregado apenas 1,5 vezes maior que as não diversificadas, e ainda, valor de produção por unidade local 20 vezes maior. No geral, o conjunto do último quartil tem uma receita média superior de duas a dez vezes nos subsetores diversificados.

(5) Para uma informação completa dos indicadores com todos os subsetores consultar Tessarin (2018). 
Tabela 5

Razão entre os indicadores: subsetor diversificado versus não diversificado, 2013

\begin{tabular}{|c|c|c|c|c|c|c|c|c|c|c|}
\hline & $\begin{array}{l}\text { CNAE } \\
2.0\end{array}$ & Subsetores a três dígitos & $\begin{array}{c}\mathrm{PO} / \\
\mathrm{UL}\end{array}$ & $\begin{array}{l}\text { W/ } \\
\text { PO }\end{array}$ & $\begin{array}{c}\text { VBPI/ } \\
\text { PO }\end{array}$ & $\begin{array}{l}\text { VTI/ } \\
\text { PO }\end{array}$ & $\begin{array}{l}\text { RLV/ } \\
\text { PO }\end{array}$ & $\begin{array}{l}\text { VBPI/ } \\
\text { UL }\end{array}$ & $\begin{array}{l}\text { VTI/ } \\
\mathrm{UL}\end{array}$ & $\begin{array}{c}\mathrm{RLV} / \\
\mathrm{UL}\end{array}$ \\
\hline \multirow{20}{*}{ 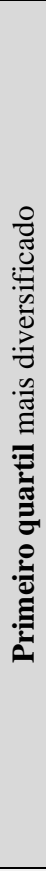 } & 265 & Instrumentos de medida & 5,7 & 1,2 & 1,8 & 1,0 & 1,7 & 10,2 & 5,8 & 9,7 \\
\hline & 332 & Instalação de M\&E & 4,1 & 2,5 & 2,6 & 1,3 & 4,6 & 10,5 & 5,3 & 18,6 \\
\hline & 172 & Papel, cartolina, papel-cartão & 3,5 & 1,2 & 1,2 & 1,8 & 1,2 & 4,3 & 6,2 & 4,2 \\
\hline & 233 & Artefatos de concreto e gesso & 3,3 & 2,6 & 3,2 & 2,8 & 3,1 & 10,5 & 9,3 & 10,2 \\
\hline & 263 & Equipamentos de comunicação & 24,3 & 1,8 & 4,0 & 4,3 & 3,1 & 96,2 & 104,8 & 75,2 \\
\hline & 209 & Preparados químicos diversos & 5,5 & 1,0 & 1,1 & 1,1 & 1,1 & 6,3 & 6,3 & 6,1 \\
\hline & 264 & Aparelhos de recepção áudio/vídeo & 7,1 & 1,5 & 2,3 & 2,8 & 2,1 & 16,3 & 20,0 & 15,3 \\
\hline & 109 & Outros produtos alimentícios & 15,9 & 1,8 & 3,6 & 3,7 & 1,8 & 57,2 & 58,1 & 28,8 \\
\hline & 174 & Produtos diversos de papel & 7,2 & 2,1 & 3,1 & 3,3 & 3,0 & 22,4 & 23,7 & 21,9 \\
\hline & 134 & Acabamentos em artefatos têxteis & 2,8 & 1,1 & 2,1 & 1,4 & 2,0 & 5,7 & 3,8 & 5,6 \\
\hline & 182 & Serviços de pré-impressão & 7,7 & 1,3 & 2,0 & 1,9 & 1,9 & 15,1 & 14,3 & 14,6 \\
\hline & 262 & Equip. de informática e periféricos & 14,0 & 0,8 & 0,8 & 0,8 & 0,7 & 11,9 & 10,7 & 10,4 \\
\hline & 239 & Pedras e minerais não-metálicos & 3,4 & 2,4 & 2,5 & 2,7 & 2,3 & 8,5 & 8,9 & 7,8 \\
\hline & 245 & Fundição & 11,3 & 1,1 & 1,2 & 1,5 & 1,2 & 13,2 & 16,5 & 13,1 \\
\hline & 202 & Químicos orgânicos & 5,1 & 1,9 & 3,5 & 3,4 & 3,5 & 17,9 & 17,7 & 17,9 \\
\hline & 122 & Produtos do fumo & 12,1 & 2,3 & 2,4 & 2,8 & 2,4 & 28,5 & 33,6 & 28,8 \\
\hline & 243 & Tubos de aço, exc. sem costura & 2,2 & 1,4 & 1,7 & 1,4 & 1,6 & 3,7 & 3,0 & 3,5 \\
\hline & 286 & Máquinas de uso industrial & 9,2 & 1,6 & 1,8 & 1,6 & 1,8 & 16,9 & 14,7 & 16,3 \\
\hline & 281 & Motores, bombas e compressores & 2,5 & 1,6 & 1,3 & 1,1 & 1,2 & 3,2 & 2,6 & 3,1 \\
\hline & 133 & Tecidos de malha & 3,1 & 1,2 & 1,0 & 1,1 & 1,0 & 3,1 & 3,4 & 3,1 \\
\hline \multirow{20}{*}{ 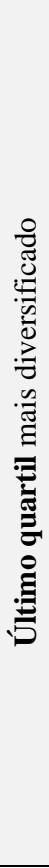 } & 141 & Confecção de vestuário & 12,9 & 1,3 & 1,5 & 1,3 & 1,3 & 18,7 & 16,8 & 16,8 \\
\hline & 111 & Bebidas alcoólicas & 8,2 & 1,0 & 2,2 & 3,2 & 2,0 & 18,1 & 26,3 & 16,3 \\
\hline & 253 & Forjaria e tratamento de metais & 4,7 & 1,4 & 1,7 & 1,9 & 1,8 & 8,1 & 9,1 & 8,4 \\
\hline & 222 & Produtos de plástico & 4,5 & 1,4 & 2,2 & 2,2 & 2,0 & 9,8 & 10,1 & 9,1 \\
\hline & 154 & Partes para calçados & 15,1 & 1,1 & 1,3 & 1,5 & 1,5 & 20,2 & 23,2 & 21,9 \\
\hline & 181 & Atividade de impressão & 2,0 & 1,6 & 2,1 & 1,9 & 2,1 & 4,2 & 3,8 & 4,2 \\
\hline & 207 & Tintas e vernizes & 5,4 & 1,0 & 1,3 & 1,4 & 1,2 & 6,9 & 7,3 & 6,7 \\
\hline & 108 & Torrefação e moagem de café & 1,8 & 2,7 & 2,3 & 2,2 & 1,9 & 4,0 & 3,9 & 3,4 \\
\hline & 183 & Reprodução de materiais gravados & 2,1 & 1,4 & 1,1 & 1,1 & 1,0 & 2,2 & 2,4 & 2,2 \\
\hline & 135 & Artefatos têxteis, exc. vestuário & 3,2 & 1,4 & 1,7 & 1,4 & 1,7 & 5,4 & 4,3 & 5,5 \\
\hline & 242 & Siderurgia & 9,2 & 1,7 & 2,5 & 2,6 & 2,4 & 22,8 & 23,6 & 22,6 \\
\hline & 282 & M\&E de uso geral & 3,1 & 1,4 & 1,5 & 1,7 & 1,5 & 4,6 & 5,1 & 4,5 \\
\hline & 293 & Cabines, carrocerias e reboques & 1,8 & 1,1 & 1,8 & 2,6 & 1,7 & 3,2 & 4,7 & 3,1 \\
\hline & 153 & Calçados & 3,5 & 1,0 & 1,5 & 2,0 & 1,5 & 5,2 & 6,9 & 5,2 \\
\hline & 244 & Metalurgia de metais não-ferrosos & 5,8 & 1,3 & 0,9 & 1,3 & 0,9 & 5,2 & 7,7 & 5,1 \\
\hline & 325 & Instrumentos médicos e ópticos & 5,7 & 1,1 & 1,3 & 1,4 & 1,3 & 7,3 & 8,2 & 7,4 \\
\hline & 201 & Químicos inorgânicos & 2,4 & 1,3 & 3,4 & 2,1 & 3,5 & 8,3 & 5,1 & 8,6 \\
\hline & 221 & Produtos de borracha & 2,7 & 1,6 & 2,3 & 2,0 & 1,9 & 6,3 & 5,6 & 5,2 \\
\hline & 231 & Vidro e produtos do vidro & 2,1 & 1,1 & 1,2 & 1,1 & 1,2 & 2,5 & 2,3 & 2,5 \\
\hline & 252 & Tanques e reservatórios metálicos & 4,8 & 1,3 & 1,5 & 1,4 & 1,5 & 7,3 & 6,6 & 7,3 \\
\hline \multirow{2}{*}{\multicolumn{3}{|c|}{$\begin{array}{l}\text { Média do primeiro quartil } \\
\text { Média do último quartil }\end{array}$}} & 7,5 & 1,6 & 2,2 & 2,1 & 2,1 & 18,1 & 18,4 & 15,7 \\
\hline & & & 5,1 & 1,4 & 1,8 & 1,8 & 1,7 & 8,5 & 9,2 & 8,3 \\
\hline
\end{tabular}

Nota: Foram excluídos os subsetores com menos de $1 \%$ de produção diversificada.

Fonte: Tabulação especial da PIA-Empresa/IBGE. Cálculos e elaboração dos autores. 


\section{Conclusão}

Este estudo investigou a diversificação produtiva da manufatura brasileira no período recente. Após identificar que os estudos nacionais estavam defasados e empregavam amostras ou medidas proxy para realizar suas análises, ele se ateve em apresentar dados diretos de produção industrial diversificada e não diversificada. $O$ estudo oferece uma novidade à literatura por apresentar informações de plantas industriais multiprodutos, sendo possível identificar o valor da produção diversificada em cada um dos subsetores para onde a diversificação ocorreu. O nível de desagregação setorial adotado é bem detalhado ao abarcar mais de 100 subsetores manufatureiros. Também se realizou uma comparação entre a parcela do subsetor diversificada em contraposição à não diversificada, fato inédito para o Brasil, que fornece elementos para identificar detalhes sobre tais diferenças.

Através de uma tabulação especial da PIA-Empresa, do IBGE, verificou-se que uma parcela pequena dos subsetores produtivos é composta por plantas produtivas diversificadas, isto é, que fabricam na mesma planta bens classificados em dois ou mais subsetores industriais. No entanto, tal parcela revelou um melhor desempenho em termos de produtividade, faturamento médio, geração de valor agregado e salário médio. As plantas industriais diversificadas realizaram $40 \%$ de toda produção manufatureira, apesar de representarem apenas 3\% das plantas industriais, indicativo de que são plantas de grande porte. Outro fato observado foi que quanto maior o nível de diversificação, melhores resultados econômicos são obtidos. Além disso, o nível de diversificação produtiva variou bastante entre os subsetores industriais. Foi possível encontrar um padrão em que subsetores de baixa e média-baixa tecnologia tendem a concentrar os esforços produtivos nos subsetores que envolvem competências similares (diversificação intraindústria). Já os subsetores de alta e média-alta diversificaram tanto para subsetores próximos como para mais distantes (interindústria), indicando que subsetores de maior complexidade tecnológica possuem capacidades técnico-produtivas aplicáveis a um conjunto mais amplo de subsetores.

\section{Referências bibliográficas}

AGHION, P.; HOWITT, P. A model of growth through creative destruction. Econometrica, v. 60, n. 2, p. 323-351, 1992.

AOKI, M.; YOSHIKAWA, H. Demand saturation-creation and economic growth. Journal of Economic Behavior \& Organization, v. 48, p. 127-154, 2002.

ARDISSONE, M. S. R. Mudança na distribuição espacial das atividades industriais por microrregião no período 1996/2005. 2009. Tese (Doutorado)-Instituto de Economia/UFRJ. Rio de Janeiro, 2009.

BARROS, A. A. de; SIDSAMER, S. Diversificação e concentração na indústria brasileira - 1974. Rio de Janeiro: IBGE, 1983.

BERNARD, A.; REDDING, S.; SCHOTT, P. Multiple-product firms and product switching. American Economic Review, v. 100, n. 1, p. 70-97, 2010. 
Milene Simone Tessarin, Paulo César Morceiro, Joaquim José Martins Guilhoto

COHEN, W. M.; LEVINTHAL, D. A. Absorptive capacity: a new perspective on learning and innovation. Administrative Science Quarterly, v. 35, n. 1, p. 128-152, 1990.

GARCIA-VEGA, M. Does technological diversification promote innovation? An empirical analysis for European firms. Research Policy, v. 35, n. 2, p. 230-246, 2006.

GORECKI, P. K. The measurement of enterprise diversification. The Review of Economics and Statistics, v. 56, n. 3, p. 399, Aug. 1974.

GORT, M. Diversification and integration in American industry. Cambridge, Massachussets: Greenwood Press, 1962.

GRANSTRAND, O. Towards a theory of the technology-based firm. Research Policy, v. 27, n. 5, p. 465-489, 1998.

GRANSTRAND, O.; PATEL, P.; PAVITT, K. Multi-technology corporations: why they have "distributed" rather than "distinctive core" competencies. California Management Review, v. 39, n. 4, p. 8-25, 1997.

HAUSMANN, R.; HIDALGO, C.; BUSTOS, S.; COSCIA, M.; SIMOES, A.; YILDIRIM, M. A. The Atlas of economic complexity: mapping paths to prosperity. Cambridge, Massachusetts, London: The MIT Press, 2013.

HAUSMANN, R.; RODRIK, D. Economic development as self-discovery. Journal of Development Economics, v. 72, n. 2, p. 603-633, 2003.

HIDALGO, C.; KLINGER, B.; BARABÁSI, A.-L.; HAUSMANN, R. The product space conditions the development of nations. Science, v. 317, n. 5837, p. 482-487, 2007.

HITT, M. A.; HOSKISSON, R. E.; KIM, H. International diversification: effects on innovation and firm performance in product-diversified firms. Academy of Management Journal, v. 40, n. 4, p. 767798, 1997.

HOLANDA FILHO, S. B. de. Estrutura industrial no Brasil: concentração e diversificação. Rio de Janeiro: IPEA/INPES, 1983.

IBGE. Pesquisa Industrial Anual Empresa: 2013. 32. ed. Rio de Janeiro: IBGE, 2013.

IBGE. Pesquisa Industrial Anual Empresa: 2016. 35. ed. Rio de Janeiro: IBGE, 2016.

JACOBS, J. The economy of cities. New York: Random House, 1969.

JACQUEMIN, A. P.; BERRY, C. H. Entropy measure of diversification and corporate growth. The Journal of Industrial Economics, v. 27, n. 4, p. 359-369, 1979.

JAFFE, A. B. Technological opportunity and spillovers of R\&D: evidence from firms' patents, profits, and market value. The American Economic Review, v. 76, n. 5, p. 984-1001, 1986.

KIM, J.; LEE, C. Y.; CHO, Y. Technological diversification, core-technology competence, and firm growth. Research Policy, v. 45, n. 1, p. 113-124, 2016.

KOREN, M.; TENREYRO, S. Technological diversification. American Economic Review, v. 103, n. 1, p. 378-414, 2013. 
KRETZER, J. A diversificação da estrutura produtiva no Brasil: observações preliminares. Revista de Economia Contemporânea, v. 19, n. 2, p. 280-306, 2015.

LOS, B. The empirical performance of a new inter-industry technology spillover measure. In: SAVIOTTI, P. P.; NOOTEBOOM, B. (Ed.). Technology and knowledge: from the firm to innovation systems. London: Elgar Publishing, 2000.

MILLER, L. M. Diversificação das empresas indutriais no Brasil: 1974. Pesquisa e Planejamento Econômico, v. 11, n. 2, p. 469-498, 1981.

MORCEIRO, P. C. A indústria brasileira no limiar do século XXI: uma análise da sua evolução estrutural, comercial e tecnológica. 2018. Tese (Doutorado)-Faculdade de Economia, Administração e Contabilidade, Universidade de São Paulo, São Paulo, 2018.

MORCEIRO, P. C.; GUILHOTO, J. J. M. Adensamento produtivo e esgarçamento do tecido industrial brasileiro. Economia e Sociedade, v. 29, n. 3, p. 835-860, 2020.

NEFFKE, F.; HENNING, M. S.; BOSCHMA, R. How do regions diversify over time? Industry relatedness and the development of new growth paths in regions. Economic Geography, v. 87, n. 3, p. 237-265, 2011.

OECD. Science, Technology and Industry Scoreboard 2003. Paris: OECD, 2003.

PALEPU, K. Diversification strategy, profit performance and the entropy measure. Strategic Management Journal, v. 6, n. 3, p. 239-255, 1985.

PAVITT, K. Sectoral patterns of technical change: Towards a taxonomy and a theory. Research Policy, v. 13, p. 343-373, 1984.

PENROSE, E. The theory of the growth of the firm. 4. ed. New York: Oxford University Press, 1959.

PÉREZ, C. Dinamismo tecnológico e inclusión social en América Latina: una estrategia de desarrollo productivo basada en los recursos naturales. Revista CEPAL, v. 100, p. 123-145, 2010.

ROBERTSON, P. L.; PATEL, P. R. New wine in old bottles: technological diffusion in developed economies. Research Policy, v. 36, n. 5, p. 708-721, 2007.

RODRIK, D. The past, present, and future of economic growth. Challenge, v. 57, n. 3, p. 5-39, 2014.

ROMER, P. Endogenous technological change. Journal of Political Economy, v. 98, n. 5, Part 2, p. S71-S102, 1990.

RUMELT, R. P. Strategy, structure and economic performance. Boston: Harvard Business School Press, 1974.

SAVIOTTI, P. P. Structural change and economic development: the role of consumption. DIME Conference: Demand, Innovation and Industrial Dynamics, p. 1-17, 2008.

SAVIOTTI, P. P.; PYKA, A. Economic development by the creation of new sectors. Journal of Evolutionary Economics, v. 14, n. 1, p. 1-35, 2004.

SCHUMPETER, J. A. Capitalism, socialism \& democracy. London and New York: Routledge, 1942. 
Milene Simone Tessarin, Paulo César Morceiro, Joaquim José Martins Guilhoto

SOLOW, R. M. Technical change and the aggregate production function. The Review of Economics and Statistics, v. 39, n. 3, p. 312-320, 1957.

TEECE, D. J. Towards an economic theory of the multiproduct firm. Journal of Economic Behavior and Organization, v. 3, n. 1, p. 39-63, 1982.

TEECE, D. J.; WINTER, S. G. Theory corporate coherence. Journal of Economic Behavior and Organization, v. 23, p. 1-30, 1994.

TESSARIN, M. S. O papel da inovação, diversificação e vizinhança setorial no desenvolvimento industrial recente do Brasil. 2018. Tese (Doutorado)-Faculdade de Economia, Administração e Contabilidade, Universidade de São Paulo, São Paulo, 2018.

TESSARIN, M. S.; MORCEIRO, P. C.; CHAGAS, A. L. S.; GUILHOTO, J. J. M. Proximidade setorial na indústria de transformação brasileira. Nova Economia, v. 30, n. 3, p. 771-801, 2020.

TESSARIN, M. S.; SUZIGAN, W.; GUILHOTO, J. J. M. Cooperação para inovar no Brasil: diferenças segundo a intensidade tecnológica e a origem do capital das empresas. Estudos Econômicos, v. 50, n. 4, p. 671-704, 2020.

ZAHAVI, T.; LAVIE, D. Intra-industry diversification and firm performance. Strategic Management Journal, v. 34, n. 8, p. 978-998, Aug. 2013. 